\title{
The Rhetorics of Urban Aboriginal Place-Making: Studying Aboriginal and Non- Aboriginal Relationship Building in the Intercultural Speaking Event
}

\author{
STEPHEN K.H. Peters
}

McGill University ${ }^{1}$

\section{$1 \quad$ Introduction}

Aboriginal peoples in Canada have long struggled to set the terms of their relationship with nonAboriginal settlers and with the state more generally ${ }^{2}$. Over the past 50 years, hard fought battles over broken treaty promises and unrecognized land claims have been waged in Canadian legislatures and courts of law, sites far removed from Canada's non-Aboriginal population. As global social and economic forces bring people of all backgrounds to urban Canada, Aboriginal people and Settlers are coming face-to-face more than ever. From art galleries to cultural festivals, panel talks to political rallies, new fronts are opening that allow Aboriginal people to not only seek redress over ongoing colonial injustice, but also to perform an Aboriginal presence that challenges other assiduous social wrongs, namely, pervasive assumptions endemic in Canadian society about the (non)place of Aboriginal cultures in modern, Western cities. Joining the courtroom and parliament floor are platform events emerging as important sites for re-writing the Aboriginal and non-Aboriginal relationship.

This paper takes up a particular class of public, Aboriginal platform events, what can be glossed as "Aboriginal, intercultural public speaking event." These are popular education events that feature Aboriginal speakers speaking about issues that affect Aboriginal life and that are primarily addressed to non-Aboriginal audiences. Since the Idle No More movement ${ }^{3}$, and with growing public concern over the environmental costs associated with resource extraction, there has been a rise in the number of these events across Canada. After two centuries of being spoken

1 Thanks to Anthony Paré for his helpful comments on earlier drafts of this paper and Erin Sirett for hers on the final ones. This research has been supported financially by the Fonds de recherche du Québec-société et la culture (FRQSC) and the Social Sciences and Humanities Research Council (SSHRC).

2 Collective terms used to designate the original peoples of the Americas have always been troublesome. With the United Nations 2008 Declaration on the Rights of Indigenous Peoples the term "Indigenous" has gained favor in Canada and is widely used in activist circles, joining local movements with a wider global struggle. "Aboriginal" is a colonial term; there were, of course, no "Aboriginals" prior to European contact, only people and the various nations to which they belonged. The term (which includes First Nations, Inuit, and Métis) has also been criticized by Kanien'kehá:ka scholar Taiaike Alfred (2005) as bureaucratic and fossilizing. It remains, however, the term of preference in scholarship and policy, and because this paper is an instance of scholarship, I use it here rather than servicing "Indigenous" to the same ends. I also use "Aboriginal" because (to me) it signals the Canadian context which this paper addresses. In the end, the problem is not so much the collective term used but that Canadians continue to organize ourselves in such a way that collective terms are indispensable. "Settler," on the other hand, is increasingly used to identify non-Aboriginal Canadians (as well as their relatively recent arrival). 
for, these talks are relatively new and promising opportunities for Aboriginal people to speak on their own behalf. I am interested in these talks as new strategies in Aboriginal peoples' battles over resource management, treaty recognition, and social inclusion. But I am also interested in them as a kind of discourse activity - a genre of interaction that may, like the textbook or museum display, have implications for the ways in which non-Aboriginal people understand and relate to their Aboriginal counter-parts in urban contexts. How (if at all) can researchers begin to appreciate the social consequence of this practice of communicating? In what ways can researchers untangle its broader importance, particularly as they occur in spaces where Aboriginal presence has been largely erased? In this paper, I aim, primarily, to establish the case for researching these events as key moments in the production of cultural difference and to explore how a rhetorically grounded discourse analysis might shed light on the larger social force of this kind of intercultural engagement.

But in doing so, and in hopes of responding more broadly to issues of diversity and language as it has been shaped by globalization, I also want to make the case that attention to spaces, places, and practices of difference-making be prioritized in sociolinguistic work on diversity - that is, prioritizing the "how" of difference rather than the "what." While such a rhetorical approach might be particularly appropriate for Aboriginal or "fourth-world" communities, where centuries of colonial meddling complicate the ways in which cultural continuity and cultural change might be practiced and tracked, I think the lesson applies more generally: whenever sociolinguists take up issues of diversity, familiar concerns with difference - with what is or is not distinctive about individuals or groups - might be better replaced with a focus on the communicative situations in which difference is expressed and becomes meaningful. Sociolinguistic research into diversity may have more to say about the kinds of things we do than the kinds of people we are.

With these goals in mind, this paper explores two public speaking events that took place late 2013 and early 2014 in Montreal, Quebec. After a short reflection on globalization and Aboriginal communities, I will examine the first event, a brief self-introduction by a young Onondaga activist, drawing on current trends in sociolinguistic research into diversity. Both the speech event and the analytical approach appear limited from the perspective of the other, suggesting that a full appreciation of the self-introduction requires a different tack. I then try to build a case for shifting the ground of sociolinguistic inquiry from "participant-focused" to "situation-focused" by situating this work in the wider scholarship on the "translation" of culture before taking up the second talk. The sequence of episodes from this talk serve as a fairly lucid example of how the situation of the intercultural public talk bears on what can be said and who speakers can be.

3 Borne in Saskatoon, Saskatchewan, the Idle No More movement emerged in late 2012 in response to changes to oversight of waterways through Aboriginal territory introduced by the Canadian government. The pan-Indigenous movement gained considerable support across North America and beyond throughout early 2013 and continues to mobilize on a number of fronts. The de-centralized movement spawned a number of teach-ins, workshops, round-dances, and demonstrations throughout Canada. 


\section{Globalization, Aboriginal diversity in Canada, and sociolinguistics}

Although Aboriginal people do not often figure in discussions on globalization, they are no strangers to it. For many Aboriginal people in Canada, the federal government's tireless effort to open Indigenous territory (and the resources found therein) to foreign capital is simply an extension of earlier colonial practices, with similar destructive effects to Aboriginal political, cultural, and linguistic traditions. The fight for jurisdiction over, and shared management of, the economic development of traditional Aboriginal territory is part and parcel with the tremendous work Aboriginal communities are now undertaking to re-build and revitalize their cultural heritage. Such cultural revitalization work is challenged, however, by an increased urbanization of Canada's Aboriginal population. Local economic and social opportunities for Aboriginal people have not matched the industrialization of Aboriginal territory. Many of the same push and pull forces that have led migrants from around the world to Canadian cities have likewise touched Aboriginal people. Although often overlooked, Aboriginal people are now part of the intense diversity that characterizes cities throughout North America. Over half of all Aboriginal people in Canada now live in urban areas. Canadian cities are, necessarily, becoming key sites in the struggle for Aboriginal cultural and political sovereignty.

Indeed, Aboriginal presence in urban spaces is itself a kind of politics. Widely held conceptions in Canada have long pitted Aboriginal culture and identities as incompatible with modern, urban life (see E. Peters 1996, 2009). These conceptual models, both pervasive and persistent, render Aboriginal presence in the urban landscape anachronistic, and they serve as facile explanations for the social issues many urban Aboriginal people face. And yet, despite the exclusivity of Canadian cities (owing its origin in large part to Canada's divisive Indian Act ${ }^{4}$ ), the category of "Aboriginal/Indigenous/Native" continues to remain meaningful in urban centers. Just how, within an urban context historically defined in opposition to it, Aboriginal group identity not only persists but continues to reinvent itself would appear to be a major site of inquiry with important contributions to make not only to Indigenous studies in Canada, but to cultural studies more broadly as well.

Recent work in the sociolinguistics of diversity and globalization seems well placed to address precisely this question. In an important break with earlier sociolinguistics, language ethnographers, particularly those working in Europe such as Jan Blommaert and Ben Rampton, have called into question once foundational concepts in sociolinguistics, in particular the idea that "fully-fluent" or "native" speakers' linguistic proficiency serves as the benchmark of clearly identifiable "languages" existing within discrete "speech communities" (see e.g., Blommaert

$4 \quad$ Canada's Indian Act is a colonial piece of legislation that has been in effect since the founding of Canada in 1867. The act, which applies only to First Nations in Canada and not Métis or Inuit people, governs numerous facets of Aboriginal life, including economic and political development, education, and identity, and establishes the Canadian government's fiduciary obligations to Aboriginal people. The original Act was primarily assimilationist and "civilizing," defining the processes whereby Aboriginal people could become "enfranchised" and legally lose their "Indian status" (e.g., Aboriginal women marrying non-Aboriginal men). 
2007; Rampton 2006). Pushing the vanguard of variation sociolinguistics, these authors have turned ethnographic attention to the "superdiversity" that surrounds actual language use in the socially heterogeneous spaces produced by globalization. Real language users, in the course of doing their linguistic business, draw on personal repertoires of linguistic forms that include sets of genres, registers, styles that may range across speech communities and ethno-linguistic variants. Biographical linguistic trajectories replace "mother tongues"; plurality of linguistic resources and speaker repertoires replace "mono-," "bi-," or "multilingualism."

When these older, inflexible speaker-language-variant categories are dispensed with, more nuanced indexical relationships can be identified between linguistic forms, on the one hand, and forms of group membership on the other. This opens new doors for linguistic studies of social life. As Blommaert (2013:1) recently argued, "language" is a particularly "sensitive and immediate index of diversity" as well as "one of the most sensitive and immediate indexes of social change.... Attention to the small details of language usage, offers a privileged entrance into broader and less immediate social, cultural, and political patterns." The use of different variants in the schoolyard, for example, may map the diverse social groups students belong to. But careful attention to the borrowing, mixing, and merging of linguistic forms reveals, with much greater detail, emergent (and sometimes) transitory practices of group affiliation and/or disaffiliation as school children interact within and across class, nation, and ethnic boundaries. Taking a wider view, different patterns of immigration, different entry points into national labour markets, different social and cultural alliances have brought about social transformations in urban spaces that undermine traditional ethnic, national, and religious categories. Ethnographies of language-use can serve as early indicators of social transformations underway (see e.g., Blommaert \& Rampton 2011). Thus, a fine-grained analysis of Aboriginal language-use may provide the kind of insight into emergent forms of urban Indigeneity currently ignored or otherwise invisible. Micro-analysis of the ways in which urban Aboriginal youth from different linguistic backgrounds, for example, speak to one another (and to outsiders) may point towards when, where, and how at least one sector of the urban, Aboriginal community is consolidating their identities as Aboriginal and, in doing so, re-defining (rather than abandoning) "Aboriginal" in ways meaningful to their present realities: as contemporary, but not "not-Aboriginal" for being so.

\section{$3 \quad$ Indexing Aboriginal group membership}

While this recent body of work suggests micro-analysis of colloquial, everyday uses of language may be a promising approach for understanding the emergence of new, contemporary urban Aboriginal practices of identification, there are far more evident invocations of Aboriginal life in Canadian cities that may be more appropriate starting points. In Montreal, Aboriginal identities and cultures are much more visible (and accessible for non-Aboriginal researchers like myself) in the relatively frequent public presentations and performances of Aboriginal social life and culture already introduced above. What, if anything, to make of these interactions? Beyond the 
performance of identity in unsolicited, colloquial talk, what can language research tell us about the explicit presentation of diversity?

An episode from the late 2013 talk examined in this study is illustrative of the kind of public addresses in question in this paper. It also highlights the options available for using language forms to index Aboriginal group membership. A fairly militant Montreal activist group has asked a young Onondaga woman, Jessica Barnett ${ }^{5}$, to give a talk as part of a panel of five speakers with the purpose of discussing Settler solidarity, or, in other words, how non-Aboriginal peoples can support the Aboriginal peoples' struggles for justice and self-determination. Following the talks of three other Aboriginal women, Barnett opens by introducing herself in Kanien'kéha. Opening with a self-introduction in a traditional language has become routine feature of these kinds of talks, even if the speakers' knowledge of the language does not extend far beyond introductory statements. Unique in this interaction is that Barnett borrows Kanien'kéha to do the job rather than her “own” Onondaga language. Kanien'kéha has, of late, undergone sustained revitalization efforts and is now much more accessible than Onondaga (which is down to less than 50 speakers). What follows is a transcription of the English that brackets the Kanien'kéha self-introduction ("M" refers to moderator, "S" to speaker):

Example 1: Speaker Self-introduction

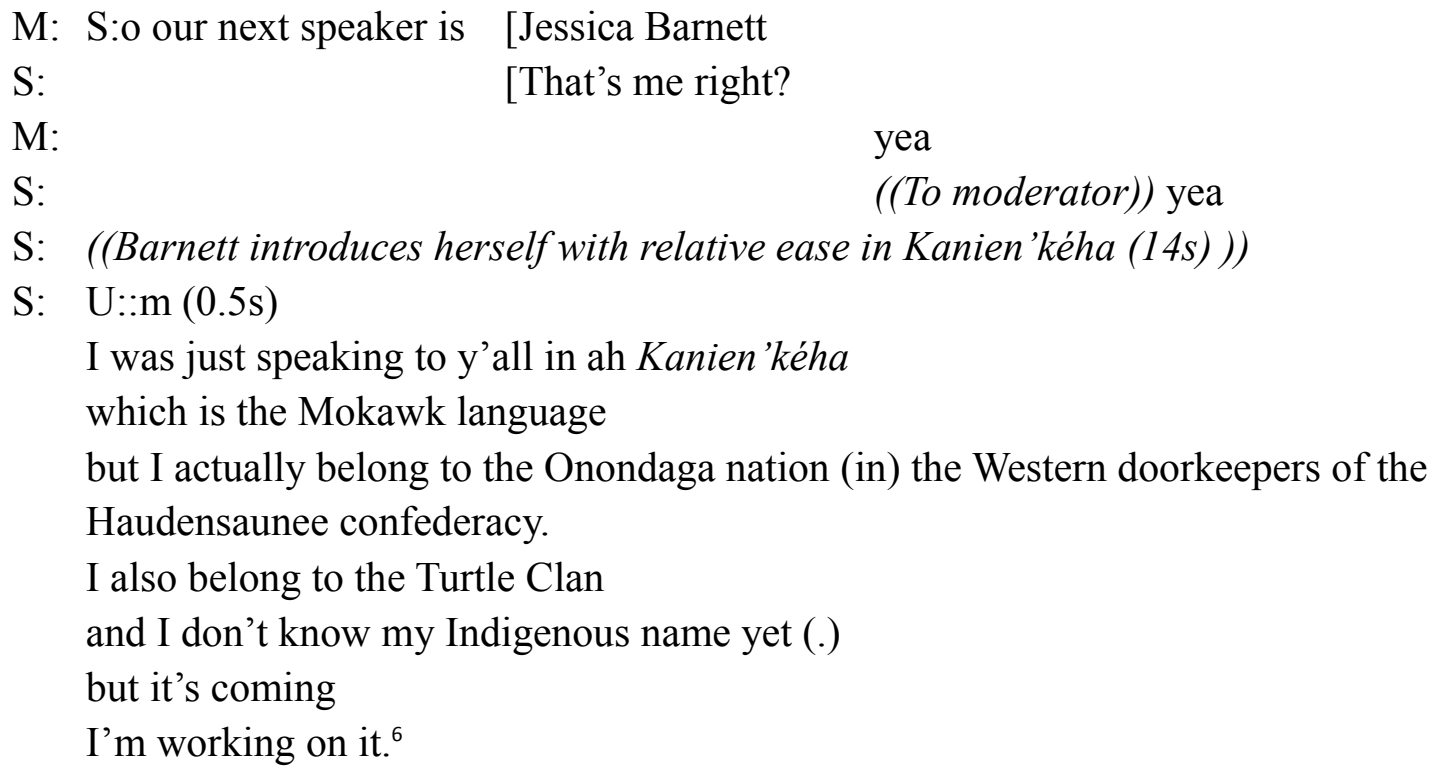

5 While the events reported here are public, pseudonyms have nevertheless been given to respect the privacy of the speakers.

6 The transcription here and in the second example below follows a simplified version of the "Jeffersonian system." See Hutchby and Wooffitt (1998) for a basic overview. Pause lengths are shown in parentheses, brief pauses are indicated by a period enclosed by parentheses, square brackets indicate overlapping speech, colons indicate stretched pronunciation, (h) indicates laughter, and finally talk placed inside parentheses represents transcribers best guess at unclear speech. 
What groups Barnett's talk with the others on the panel and the larger class of Aboriginal public speaking events is the explicit effort to relay-across cultural boundaries - Aboriginal traditions, culture, and social issues by those who can claim insider status to it. As "Orientalist" critiques of representation gain traction outside scholarly circles, embodied representatives of Aboriginal life are quickly replacing the anthropologist or social worker as the preferred authority on "all things Aboriginal." In Montreal, there have been no fewer than 14 events featuring 22 different speakers over a three-month period beginning in January, 2014. While the primary goal of these events is largely educative, they also do diversity. The embodied aspect of the talk by both speakers and audience members (as non-Aboriginal) introduces a performative quality to the talk centered on establishing and maintaining ethnic difference between speaker and hearer, as Barnett's talk makes clear.

In her case, the use of Kanien'kéha clearly serves as an explicit assertion of Aboriginal identity. It is a rather straightforward example of what Jocelyn Ahlers (2006), in her study on "the public use of Native American Languages by non-fluent speakers," called a "Native language identity marker" (NLIM). NLIM markers function primarily pragmatically rather than referentially. As Alhers (2006:58) explains, the use of NLIM "creates a discourse space in which a subsequent English speech event is understood by audience members to come from, and be informed by, a Native identity." While Alhers' study focused on communicative events involving Native speakers and audience members, her call for foregrounding the pragmatic value of NLIMs is all the stronger in intercultural speaking situations. Barnett's introduction not only signals her Aboriginal identity, it also marks her difference from the primarily non-Aboriginal audience gathered who have little if any understanding of Kanienkéha'ka.

The use of NLIM in public addresses gives evidence of new spaces for the expression of Aboriginal languages (and a radically re-envisioned function). However, from the approach generally carried out in contemporary sociolinguistics of diversity discussed earlier, its use in speech events where the Aboriginal identity of the speaker is central and established ahead of the event (e.g., in the event announcement and speaker introduction) may seem fairly self-evident. The focus of this work has been in large part concerned with cultural transgression, newness, and mixing, those fleeting moments of cultural identification that confound (rather than reinforce) inherited social categories. If language does indeed provide a powerful lens into changing social and cultural patterning, it's unsurprising that sociolinguistic work on diversity has given preference to the more ephemeral moments of identification that occur in the quick of spontaneous talk rather than self-conscious, explicit cultural statements. Rampton and Blommaert (2011:6) put it in the following way:

$[R]$ esearch ... has to address the ways in which people take on different linguistic forms as they align and disaffiliate with different groups at different moments and stages. It has to investigate how they (try to) opt in and opt out, how they perform or play with linguistic signs of group belonging, and how they develop particular trajectories of group identification throughout their lives. 
It's a fair question whether these kinds of intercultural presentations tell us much about how Aboriginal culture is "really" taking shape in Canadian cities. The code borrowing in Example 1 serves as a pretty clear instance of how language-users draw on the linguistic resources at hand to opt in to a particular group (and opt out of another). But in the context of an explicitly Aboriginal public talk addressed to outsiders, they may seem somewhat artificial and, in any event, not where the real action is.

\section{$4 \quad$ Staging difference}

Barnett's need to borrow a code to identify herself, however, is emblematic of a more general reality of urban Aboriginal Canada, one that is an outcome of Canada's colonial relationship with the Aboriginal populations insider its borders and that complicates applying the superdiversity framework for understanding the making of contemporary, urban Aboriginal identities. The urban Aboriginal community is made up of various different nations with a variety of linguistic heritages. Aboriginal people have also taken different routes to the city and have different experiences within both Aboriginal and urban communities. Some may have just arrived from remote communities. Others, because of colonial adoption policies, may have just discovered their Aboriginal heritage. ${ }^{7}$ Colonial policies have worked to splinter Aboriginal peoples to such an extent that the shared linguistic forms that might serve as indexical of collective Aboriginal belonging in urban spaces are not necessarily available for all the people who claim to be and are identified as Aboriginal. While any Aboriginal language-use might serve as means for opting in, opting in may likewise occur through self-affirmation, without the need for any indexical associations (including visual cues). Indeed, in the case of the example above, Barnett's Aboriginal status was already well secured before a word of Kanien'kéha was ever spoken.

But that the production of group identity and group membership exists apart from shared indexical forms does not mean that understanding urban Aboriginal group formation is not a job for language researchers, even if linguistic repertoires no longer appear to be of primary concern. Rather, it is in this context that the doing of cultural distinction (done, at least in part, linguistically) seems all the more worthy of careful attention. Turning our attention to the language of difference-making requires a shift in inquiry away from ethnographic description of the speaker - their trajectories, their practices of identification, the groups they belong to, and so on - and towards descriptions of the possibilities and constraints of presenting and valuing difference in particular situations. As cities become increasingly diverse, intercultural recognition becomes an ever more important force in shaping how cultural difference is lived. In city spaces dominated by a history of Aboriginal marginalization, just who you can be as an Aboriginal person (and how) is necessarily a relational, cross-cultural achievement. Apart from looking "inside" nameable social groups, research into points of contact where recognition is sought out and conferred is increasingly crucial. The urgency is with the "when," "where," and "hows" of

$7 \quad$ Throughout the 1960s the Canadian Government facilitated the adoption of Aboriginal children by nonAboriginal parents. The practice is often referred to as "the 60s scoop." 
cultural difference-making, rather than the "what" of cultural particularity. Moreover, as it concerns Aboriginal populations in Canada, such an approach may be more appropriate: for communities who have suffered from the role of Western knowledge in the colonial project, continued inquiry into "who" Aboriginal people are (or are becoming) is likely to be met with suspicion or animosity. Instead, what may be in fact more pressing is trying to determine how "Aboriginal culture" is enabled in the ways we, as both Aboriginal and non-Aborignal, collectively organize to recognize it.

There is already a rich tradition of scholarship taking up the staging of cultural identity. Public exhibitions of culture have often criticized for their inauthenticity and for oversimplifying cultural difference. The glass-box of the museum and the white walls of the art gallery, for example, have been routinely charged with inviting voyeuristic responses to Aboriginal culture. Museums, by their very function to collect and display, tend towards exoticization and risk reducing complex cultures into artefacts to be salvaged, not political forces shaping our contemporary realities (see, Ames 1992, Karp 1991, Nelson 2006). The display, circulation, and marketization of Aboriginal art have been brought about by the diligent, egalitarian ethos of art curators who have lobbied to put Aboriginal art on the same footing as Western art; the slogan here being "Art without adjectives." However, the notion that Aboriginal art should be judged "in its own right"- that once hung on the gallery wall it should transcend culture and history in search of the sublime - masks the particularity of Aboriginal ways of valuing/using the aesthetic (Fisher, 2012) and enfolds Aboriginal art into a characteristically Western propensity to universalize (and render superior) a very exclusive cultural milieu (see also, Marcus \& Myers, 1995; Myers, 2013).

The question here is to what extent do intercultural public talks continue or escape these earlier frames of interaction? Anthropologists such as Fred Myers (1991, 1994, 2013) and James Clifford (1988) have done quite significant work in drawing attention to what Myers calls "the rules of the production and reception" of cultural difference as it concerns the art world and museum curation (Myers 1994:679). Here sociolinguistic work can play an important role extending and deepening this work, establishing the rules of the production and reception of cultural difference as they are realized in the public talk, the most recent iteration of a tradition of staging Aboriginal culture for non-Aboriginal consumption. The task requires the delicacy that discourse analysis can provide. By affording opportunities for Aboriginal peoples to "speak back" directly to a colonial society that has long-denied them a voice, the public talk clearly cannot be dismissed out of hand as yet another instance of cultural objectification and commodification. Intercultural performances of Aboriginal identity necessarily enter into preexisting practices of exchange, but that does not preclude speakers' use of these practices to new and creative ends.

Following Clifford and Myers, the intercultural public speaking event can be seen as a kind of action that participates in ongoing practice of intercultural expression and recognition. Careful attention to the language forms used (whether in English, French, or Kanien'kéha) can shed light on the nature of the discourse practices: To what needs and expectations do these addresses respond? How do these obligations shape the ways the communication proceeds? In 
turn, how does the genre of the intercultural address shape the "looking relations" and intercultural relationships realized in the interaction? Finally, how do Aboriginal speakers manage the obligations of the events and pursue the possibilities they afford?

\section{Towards a rhetoric of difference-making}

The second example below brings out the situational delicacies of the intercultural address. The transcript is of an event where the speaker's speaking position becomes a particularly sensitive matter. The interplay between the obligations of the discourse practice and how these obligations are met in actual talk is dramatically demonstrated in the three segments of the talk transcribed below. The implications of the intercultural public speaking event for the ways cultural boundaries and intercultural relationships are constructed in these kinds of talks are particularly evident. The speaker is Rita Norton. Her talk was part of an environmental awareness campaign targeting the tar sands in northern Alberta organized by a US environmental action group. Environmental activism has done much to increase the public profile of and interest in Aboriginal communities. As the litany of abuses against Aboriginal people grows, the environmental movement has found a valuable ally. Aboriginal communities are often the first affected by industrial development, and the string of injustices Aboriginal people have faced throughout history hastens the urgency of the preservationist message. About 100 people came to the event. Although not particularly well known, Norton was the primary draw for the event and given twice the speaking time as the other two (non-Aboriginal) presenters. Norton belongs to a Northern Alberta Cree First Nation whose community has been directly impacted by the pollution generated by the tar sands industry. In 2008, leadership in the First Nation launched a daring legal action against the Albertan and Canadian governments, arguing that tar sands development within their traditional territory is a violation of their Treaty 6 rights. The event was organized in part to raise funds to support the lawsuit. In the promotion that circulated for the event, her talk was promised to "awaken the audience to the ... realities" of her community.

A number of notable features of the talk jump out from the transcripts. Here, however, I wish to focus attention on her efforts to locate her deitic center as she undertakes this awakening work and the eventual trouble she finds herself in locating just whose voice she is representing. The segments are of three different episodes of her talk. The first comes from very early in her talk and is typical of the "awakening" work she did throughout. In the second segment, taken from about mid-way through her presentation, she states a position on oil sands development. And in the third segment she is questioned about this position during the Q\&A ("S" refers to speaker and "Q" to questioner).

Example 2: Locating the Principal in the Intercultural Aboriginal Public Talk

Segment 1 
S: And in in return

we would share the land

because in our language

there literally is n:o word for ownership of land, we we do not have that

because when you literally translate that ownership to o:wn land

it it really it comes out in the literal English translation is y:ou cannot own your Mother.

Our mother is the one who gives us life and nurtures us.

So you cannot own her.

But we can share what our creator has given us, that's what the old people said.

\section{Segment 2}

S: Thus you know save all human beings you know taking on this fight that's gonna um ultimately protect us all ah you know and what this litigation said was you know we're not saying "shut down the tar sands."

You know what we're saying is you know the bitumin is there it's not going anywhere let's slow down here.

You know let's take a step back and reassess what's going on here and ah and so they did that and ah...

Segment 3

Q: Um thank you for your talk.

Um I would like to just clarify one emm one aspect to make sure I understood.

You said something about not wanting to say that ah you're not saying to shut down the tar sands.

Is there a reason why you would not want to say that?

S: Shit ((spoken under her breath but still in the microphone and loud enough to be heard by the audience; audience begins to laugh)) (1s) um (4s) ((Norton is smiling; laughter in the crowd progressively increases)) um ((throat clearing, laughter tapers off)) (1s)

S: my personal opinion and that opinion of my leadership and my nation as a whole a:nd our people as a whole are all different.

S:o (.) that question is very unfair to ask m:e(h) which is why I I just won't answer it because um like I said I don't represent my nation, I don't represent my leadership I represent my children and me as a citizen member of my community 
um and so I I can't answer that

you know in a private con(h)versation

me and you my personal opinion I would answer that

but I can't answer that you know

and have that out there you know

and have it misconstrued

and maybe me you know it comes out as if I'm speaking for my nation or my leadership when I don't (.5s)

sorry

Bitzer (1968:6) defined "exigence" as the "thing which is other than it should be" and which can be put right through discourse. It is helpful here for situating the underlying purpose or motivation driving the discourse and its reception in the event itself (rather than the speaker's will or as a cultural characteristic, see also Pare 2014). Clear from the promotional material discussed above, the audience has been convened to rectify a knowledge deficit concerning the impacts of the tar sands on Aboriginal communities. Her talk has been occasioned by a need to bring the audience from a state of low knowledge to higher knowledge (or to awaken them from their dormative state). This socially determined exigence has implications for the talk itself. For Norton to meet the exigence, she must speak declaratively and she's obliged to make her community the "principal" of her talk - the person or people whose beliefs and positions are told "by the words that are spoken" (Goffman 1981:181). Thus, the first segment is fairly typical of the talk as a whole. The "you" in this segment is universal, but the "we" indexes the descendants of Cree speakers whose beliefs have been shaped by the Cree language. The second segment continues this pattern, "we" indexing the community members behind the lawsuit.

But the question asked in the third segment breaks this pattern. The request for clarification: "You're not saying to shut down the tar sands. Is there a reason why you would not want to say that?" refers back to the line "you know we're not saying 'shut down the tar sands"" transcribed in the second segment. Norton's "we" is shifted to the questioner's "you." Likewise the principal shifts from the community (in segment 2) to Norton herself (or a conflation of the two together). The shift, along with Norton's clear meta-awareness of her own speaking position, puts her in a bind. She risks, on the one hand, misrepresenting her community's interests and, on the other, finding herself at odds with an environmental movement which has gathered to hear her speak. ${ }^{8}$ Her meta-talk in the third segment illustrates well the difficulty she faces extricating herself from her predicament. She states that as a representative of her community, she's not at liberty to speak freely (but could outside the context of the public talk in a private conversation) but goes on to entreat her audience to understand that as just one member of her community, she only represents her own voice and the voice of her children. Even after the qualification given,

8 The environmental group behind the event calls for a "fossil-free" future while Greenpeace calls for the stopping of the tar sands (see http://www.greenpeace.org/canada/en/campaigns/Energy/tarsands/). 
Norton does not risk voicing her own opinion, suggesting that in the end the assigned principal in the intercultural public talk, the community or culture, wins out.

This exchange is enlightening because it brings to the level of explicit reflection within the event itself the rhetorical structure that surrounds it. The ambivalence around speaking position and the meta-talk it provoked is not unique to Norton's talk. The tendency to fold all Aboriginal culture into the speaker is something many Aboriginal speakers explicitly flag in their presentations. Choosing who gets to speak can play politics in Aboriginal communities, and speakers are often cognizant of the political nature of the act of giving a public talk. Spaces for recognizing Aboriginal culture are necessarily spaces for conferring value on it as well. Public talks are occasions for assigning what and who should be valued. In her talk, Norton is tasked with having to reconcile Cree culture as something the environmental movement ought to appreciate (having no language to express ownership of land) with the reality that Cree people are like all people: they debate, hold various opinions, negotiate present circumstances, and, sometimes, believe in a future that includes oil and gas development. To what extent are the representational quandaries inevitably tied up with the discourse genre of the public talk? In what ways can speakers distance themselves from the politics of the organizers? What pressures are placed on speakers and audience members when identity and authority presume the other?

\section{Conclusion}

The analytical effort when researching the situation of intercultural interaction is not a critical one, at least not in the regular sense of the word. Rather the goal is to describe as completely as possible the ways talk attaches itself to the course of events which has invited the talk and which the talk helps realize (McDermott 1988). Ethnographies of communication in the tradition of Dell Hymes (1974) are important starting points here as they have been contemporary ethnographers of language and diversity. However, to continue the work of Clifford and Myers, the functional language form that ethnographies of communication reveal need to be understood, not simply as characteristic of social groups, but responding rhetorically to the social activity of which the communication is a part. Here recent work in rhetorical genre can serve as a useful complement to arsenal developed in linguistic anthropology (e.g., Bawarshi and Reiff 2010, Devitt 1993, Miller 1984).

The Aboriginal public intercultural address is, as I said earlier, an important avenue for Aboriginal people to speak back to Settler society. But they clearly carry their own political implications. What I've tried to do in this paper is suggest an approach to researching cultural diversity that is not too concerned with what actually constitutes the cultures under study. One advantage for a researcher like me, a non-Aboriginal white male, is that taking the focus off culture and/or the identities of my participants reduces the concerns around ethno-centric projections of cultural minorities. Instead, as we see in Norton's talk, issues around cultural authority, representation, and reification become part of the study itself. Vitriolic comments have been circulating around the web about Barnett being a "fake Indian." Her borrowing of Kanien'kéha might serve either side of the debate. But in many ways, it's not a debate for 
cultural commentators to enter into. Language ethnographers like Blommaert and Rampton and many others have shown the tremendous complexities in the ways groups actually form and reform on the ground. One of the consequences is that just where group boundaries lie is forever receding from view. On the other hand, cultures, ethnicities, races, genders are made to have meaning all the time. By turning attention away from the participants and towards the situations and social activities in which cultural diversity is done, sociolinguistic research has important contributions to make in unearthing processes in which groups are both negotiated and consolidated.

\section{$7 \quad$ References}

Alfred, Taiaiake. 2005. Wasáse: Indigenous Pathways of Action and Freedom. Peterborough: Broadview Press.

Ames, Michael M. 1992. Cannibal Tours and Glass Boxes: The Anthropology of Museums. Vancouver: UBC Press.

Alhers, Jocelyn. 2006. Framing Discourse: Creating Community through Native Language Use. Journal of Linguistic Anthropology 16(1):58-75.

Bawarshi, Anis S and Reiff, Mary Jo. 2010. Genre: An Introduction to History, Theory, Research, and Pedagogy. West Lafayette: Parlor Press.

Bitzer, Loyd F. 1968. The rhetorical situation. Philosophy \& Rhetoric 1(1):1-14.

Blommaert, Jan. 2007. Sociolinguistics and Discourse Analysis: Orders of Indexicality and Polycentricity. Journal of Multicultural Discourses 2(2):115-130.

Blommaert, Jan. 2013. Language and the study of diversity. Tilburg Papers in Culture Studies 74:1-14.

Blommaert, Jan and Rampton, Ben. 2011. Langauge and Superdiversity: A Position Paper. Working Papers in Urban Langauge \& Literacies 70:1-22.

Clifford, James. 1988. The Predicament of Culture: Twentieth-Century Ethnography, Literature, and Art. Cambridge: Harvard University Press.

Devitt, Amy J. 1993. Generalizing about Genre: New Conceptions of an Old Concept. College Composition and Communication 44:573-586.

Fisher, Laura. 2012. The Art/Ethnography Binary: Post-Colonial Tensions within the Field of Australian Aboriginal Art. Cultural Sociology 6:251-270.

Goffman, Erving. 1981. Forms of talk. Philadelphia: University of Pennsylvania Press. 
Hutchby, Ian and Wooffitt, Robin. 2008. Conversation analysis. Cambridge: Polity.

Hymes, Dell. 1974. Foundations in Sociolinguistics. Philadelphia: University of Pennsylvania Press.

Karp, Ivan. 1991. Exhibiting Cultures. In Ian Karp and S Lavine, eds., Exhibiting Cultures: The Poetics and Politics of Museum Display, pp. 11-24. Washington: Smithsonian Institution Press.

Marcus, George E and Myers, Fred R. 1995. The Traffic in Culture: Refiguring Art and Anthropology. Berkeley: University of California Press.

McDermott, Ray P. 1988. Inarticulateness. In D. Tannen, ed., Linguistics in Context, pp. 37-68. Norwood: Ablex.

Miller, Carolyn. 1984. Genre as Social Action. Quarterly Journal of Speech 70:151-167.

Myers, Fred. 1991. Representing Culture: The Production of Discourse(s) for Aboriginal Acrylic Paintings. Cultural Anthropology 6(1):26-62.

Myers, Fred R. 1994. Culture-Making: Performing Aboriginality at the Asia Society Gallery. American Ethnologist 21(4):679-699.

Myers, Fred R. 2013. Disturbances in the Field: Exhibiting Aboriginal Art in the US. Journal of Sociology 49(2-3):151-172.

Nelson, Mellissa., 2006. Ravens, Storms, and the Ecological Indian at the National Museum of the American Indian. Wicazo Sa Review 21(2):41-60.

Paré, Anthony. 2014. Rhetorical Genre Theory and Academic Literacy. Journal of Academic Language and Learning 8(1):A-83-A-94.

Peters, Evelyn J. 1996. 'Urban' and 'Aboriginal': An Impossible Contradiction. In J Caufield and L Peake, eds., City Lives and City Forms: Critical Research and Canadian Urbanism, pp. 47-62. Toronto: Toronto University Press.

Peters, Evelyn J. 2009. Aboriginal Peoples in Urban Areas. In H. Hiller, ed., Urban Canada: Sociological Perspectives, pp. 156-174. Don Mills: Oxford University Press.

Rampton, Ben. 2006. Language in Late Modernity: Interaction in an Urban School. Cambridge: Cambridge University Press.

Senghor, Léopold S. 1966. Senegal's President explains Negritude, The Afro American, October $8: 5$. 